19 Revue d'histoire du XIXe siècle

Société d'histoire de la révolution de 1848 et des

révolutions du XIXe siècle

$26 / 27 \mid 2003$

Varia

\title{
Le drame de la nuit : enjeux médico-légaux du quadruple égorgement commis en 1885 à Genève par une mère sur ses enfants
}

\section{Michel Porret}

\section{(2) OpenEdition}

Édition électronique

URL : https://journals.openedition.org/rh19/753

DOI : $10.4000 /$ rh19.753

ISSN : $1777-5329$

Éditeur

La Société de 1848

Édition imprimée

Date de publication : 1 décembre 2003

Pagination : 305-329

ISSN : 1265-1354

\section{Référence électronique}

Michel Porret, « Le drame de la nuit : enjeux médico-légaux du quadruple égorgement commis en

1885 à Genève par une mère sur ses enfants », Revue d'histoire du XIXe siècle [En ligne], 26/27 | 2003,

mis en ligne le 19 février 2008, consulté le 28 février 2022. URL : http://journals.openedition.org/

rh19/753; DOI : https://doi.org/10.4000/rh19.753

Ce document a été généré automatiquement le 28 février 2022.

Tous droits réservés 


\title{
Le drame de la nuit : enjeux médico- légaux du quadruple égorgement commis en 1885 à Genève par une mère sur ses enfants ${ }^{1}$
}

\author{
Michel Porret
}

\section{NOTE DE L'ÉDITEUR}

À Alain Corbin

\begin{abstract}
« Et vous croyez raisonnable cette mère qui adore son enfant, et qui cependant lui plonge le poignard dans le sein! Il n'y aurait pas chez cette malheureuse quelque altération, non seulement de la sensibilité, mais aussi de l'intelligence, alors que, malgré sa tendresse, malgré l'horreur que lui inspire son désir, elle prépare et donne la mort à

son enfant aimé ». E. ESQUIROL, Des Maladies mentales considérées sous les rapports médical, hygiénique et médico-légal, Paris, 1838 (2 vol.), II, p.
\end{abstract}

Après l'affaire de la garde-malade Marie Jeanneret (âgée de 32 ans) condamnée le 29 novembre 1868 à vingt ans de travaux forcés devant les Assises genevoises pour avoir empoisonné neuf patients ${ }^{2}$, le crime de Coutance est le cas judiciaire le plus important instruit et jugé à Genève à l'aube de la Belle Époque. Sa gravité ressort des 182 pièces judiciaires du procès instruit entre le 2 mai 1885 et fin mai 1886 par le juge Charles-Henri Léchet contre Jeanne Lombardi, née Deluermoz le 8 juin 1853 à Vétraz (Haute-Savoie) ${ }^{3}$. De « taille moyenne avec assez d'embonpoint ", de teint pâle, la « tête bien conformée ", veuve en première noce de son ancien patron le marchand Balleydier 
dont elle a été la maitresse avant le décès de sa femme, Jeanne a épousé en octobre 1876 le tailleur Joseph Lombardi. L'homme, né à Carouge (localité voisine de Genève) en 1853, est de taille moyenne $(1,76 \mathrm{~m}$.) selon son passeport, qui précise «teint naturel ", "visage ovale», "barbe montante», "bouche moyenne» et "yeux gris-bleus", " cheveux châtains » mais " grisonnants ». L'impact moral du crime est immédiatement signalé par une brochure anonyme publiée à Carouge : «Jamais encore un drame aussi lamentable n'a occupé l'attention publique. Il nous est presque impossible d'apprécier le sens et la signification morale et philosophique du drame effrayant qui vient de s'accomplir à Genève " ${ }^{4}$. Ayant " profondément ému la population " (Tribune de Genève, 9 mai) d'une ville peuplée d'environ 60000 habitants, il fait écho aux pages les plus sombres de la littérature populaire du XIX ${ }^{\mathrm{e}}$ siècle.

Ce crime maternel illustre la complexité d'un fait social que représente le massacre de quatre enfants « innocents » commis dans une ville bourgeoise et protestante dont les élites radicales comptent encore sur la philanthropie et le paternalisme politique pour résoudre la question sociale. Survenu dans le faubourg, que les autorités veulent alors assainir sur le plan moral et matériel en raison de sa « létalité " particulière ${ }^{5}$, ce crime jette une " ombre lugubre » sur la société genevoise. Il suscite l'hébétude et la curiosité collectives. Le choc moral de la ville ressort notamment des attroupements nocturnes dans la rue de Coutance où, devant la boutique du tailleur Lombardi, maints curieux veulent « voir les cercueils des enfants » égorgés par leur mère. Morbide, la curiosité sociale culmine, peut-être, dans la bousculade des nombreux badauds qui tentent de forcer la porte de la Morgue pour « jeter un coup d'œil sur les [...] petits cadavres ». Si le drame de la nuit provoque l'empathie des "masses" qui suivent le "convoi funèbre " des victimes, il se mue en un fait divers intolérable que construit la presse, protestante et catholique, conservatrice, libérale et radicale ${ }^{6}$. La presse confessionnelle d'opinion fustige d'ailleurs la curiosité collective et malsaine qu'entretiennent les quotidiens populaires. Le 9 mai 1885, La Semaine religieuse de Genève, organe hebdomadaire du protestantisme évangélique, dénonce l'exploitation médiatique du crime de Coutance: "On incite les journaux quotidiens à remplir leurs colonnes de détails inédits sur le drame de Saint-Gervais ; l'on s'arrache les exemplaires de celui qui donne le plan du théâtre du crime [Tribune de Genève, 2 mai 1885], et l'on fait monter son tirage du chiffre de 8500 à 13698 ». L'« atrocité » du drame provient de sa violence extrême - quatre enfants égorgés, trois morts, un survivant-, ainsi que du déchirement des rôles sociaux de ses protagonistes : père dépravé, mère "dénaturée ", voisinage impuissant dans sa solidarité. Pour les observateurs du drame, seule l'amnésie collective purgera Genève du souvenir de la mère égorgeuse dont la démence ne peut qu'expliquer le passage à l'acte. Telle est l'idée du correspondant "particulier » de la Gazette de Lausanne (8 mai): "Une fois que cette femme a pu faire des aveux complets, qu'aucun doute ne peut planer sur son mari ou sur toute autre personne, n'est-il pas à souhaiter qu'elle trouve le plus tôt possible dans la folie l'oubli de ce qui s'est passé : [...] il est indifférent que cette mère sauvage soit désormais dans une maison d'aliénés, dans la cellule d'une prison ou même dans le tombeau. Qu'on fasse donc le plus tôt possible le silence sur ce drame épouvantable qui confond la raison, et dont notre population ne gardera que trop longtemps le funèbre souvenir! » Après l'émotion collective née du quadruple égorgement spectaculairement mis en scène par la presse genevoise, le recueillement du silence social est censé gommer le sens d'un crime qui place la représentation de la famille sous le signe du mal absolu.

Science, vérité, justice 
3 L'étude inédite du crime de Coutance s'insère dans une recherche concernant l'histoire des pratiques médico-légales entre le XVII ${ }^{e}$ siècle et la fin du XIX ${ }^{e}$ siècle ${ }^{7}$. Induite par la procédure inquisitoire (écrite, secrète et basée sur un système probatoire rationnel aveu, expertises) qui s'impose en Europe continentale dès la Renaissance, la médecine judiciaire de l'Ancien régime, empirique, matérialiste et pratique, prépare le terrain institutionnel de la médecine légale du XIXe siècle. Crimes de sang, crimes sexuels, empoisonnements, suicides, accidents : autour du corps violenté, les savoirs diffus du légiste traditionnel se métamorphosent lentement, surtout durant le siècle des Lumières, en la discipline constituée de la médecine légale scientifique. Tiré du latin «medicina forensis " (médecine du forum), le concept de "médecine légale », qui soude la pratique judiciaire aux usages médicaux, est un néologisme en français dès l'article du médecin Jean Lafossse en 1777 dans le Supplément de l'Encyclopédie Diderot et d'Alembert. Il en prône l'« objectivité » scientifique: "Dans la disette des preuves positives qui sont du ressort de la magistrature, on consulte les médecins et les chirurgiens pour établir par des preuves scientifiques, l'existence d'un fait qu'on ne saurait connaître que par ce moyen. Leur décision devient alors la base du jugement et doit en garantir la certitude et la justice ${ }^{8}$. Après la décennie $1790-1800$, partout en Europe continentale le terrain médico-légal ne cesse de croître dans la culture et les usages judiciaires. Idéalement, le légiste veut objectiver la preuve du crime par des protocoles d'expertises qui aspirent à prouver la «certitude » du passage à l'acte criminel en en quantifiant les circonstances morales et matérielles. La nature du crime et le mode opératoire se mesurent notamment sur le corps violenté. Au siècle de Lacassagne et de Lombroso, le légiste assermenté devient définitivement l'allié de la justice criminelle. Dans son institut, durant l'instruction et devant les assises, l'expert aide le juge à qualifier positivement le crime de sang ou le délit sexuel selon leurs pathologies ${ }^{9}$. Il examine le corps violenté, en détaille les plaies. Il arpente les lieux du crime pour en dresser la topographie ${ }^{10}$. Son objectif : déterminer le mobile, quantifier le mode opératoire de l'homo criminalis, en cerner la personnalité, en estimer la récidive pour la juguler. D'Alexandre Lacassagne à Edmond Locard, les grands légistes défendent la modernité sociale et la supériorité scientifique de leur discipline par rapport à la pratique médicale des généralistes. Ils prônent une science « objective » du crime. En 1885, le légiste Henri Legrand Du Saulle en résume le credo positiviste: la «science exacte » du crime doit « sceller définitivement et de la manière la plus durable les trois termes de cette admirable devise de la médecine légale [...] : Science, Vérité, Justice » ${ }^{11}$.

4 Appuyé sur les expertises psychiatriques qui médicalisent l'instruction du crime de Coutance, ce cas évoque les liens pratiques et épistémologiques entre l'enquête judiciaire, la médecine légale de la personnalité criminelle et du corps violenté. Dans une finalité pénale, il donne sens aux enjeux de la criminologie et souligne la qualification psychiatrique de la responsabilité et de l'irresponsabilité criminelles selon la nosographie incertaine de l'aliénation mentale. Folie morale ou nerveuse, manie, atavisme familial et dégénérescence, névrose : la "tyrannie » de la désorganisation mentale du fou mobilise les aliénistes pourtant divisés sur la vérité de l'aliénation mentale (néologisme en français vers 1811). Si celle-ci transforme l'homo criminalis en malade et conduit le médecin à en étudier la biographie, le langage, la personnalité ou l'écriture pour énoncer l'histoire de la folie et théoriser son traitement, la nature même de l'état mental pathologique est incertaine. Une «ligne nette et sûre » entre la " sanité » et l'« insanité » mentales est improbable pour qualifier le crime commis par un «aliéné », affirme en 1874 Henri Maudsley, professeur de médecine légale à 
l'University College de Londres, qui plaide pourtant pour une science mentale "positive ${ }^{12}$. Fratricide, parricide, infanticide, «tueur de femmes » : la monstruosité $\mathrm{du}$ fou criminel ou pervers brouille les catégories des délits de droit commun. Elle nourrit la chronique des faits divers ruraux ou urbains que la presse populaire, à l'instar du Petit Journal en France, inscrit dans une politique éditoriale de l'information spectaculaire qui pointe notamment l'insécurité et le «laxisme» des tribunaux en exploitant la biographie des criminels ${ }^{13}$. Or, s'il est déclaré aliéné par les experts, l'homo criminalis est donc un malade : les symptômes de son état mental pathologique constituent la nosographie positive du crime.

5 L'enjeu de l'expertise médico-légale est immense pour l'issue du procès criminel. Elle détermine la responsabilité ou l'irresponsabilité de l'accusé, le soumet à la peine ou à un traitement médical, selon ce que prévoit l'article 64 du Code pénal français de 1801 : « il n'y a ni crime ni délit, lorsque le prévenu était en état de démence au temps de l'action, ou lorsque qu'il a été contraint par une force à laquelle il n'y pas pu résister ». Dans ce cadre juridique, les légistes et les psychiatres diagnostiquent les perturbations de la folie dans le comportement humain: insanité résultant du délire ou d'hallucinations, passage à l'acte dangereux né d'une impulsion irrésistible ou d'une " hérédité atavique ", affections mentales caractérisées par la faiblesse d'esprit, gestes « irrationnels » commis sous l'influence d'une névrose ou d'un autre état pathologique nerveux, comme la manie, la mélancolie, ou l'hystérie. Tel est, à grands traits, le contexte médico-légal du crime de Coutance qui divise les experts, bouleverse la population genevoise entre mai 1885 et juin 1886. Mal connu encore ${ }^{14}$, ce cas criminel illustre l'impact crucial de la médecine légale, de la psychiatrie et de la criminologie sur les pratiques judiciaires qui visent à objectiver la qualification des délits. Dès les années 1850, la justice genevoise est progressivement modernisée par les pratiques de la médecine et de la psychiatrie légales. En raison de la gravité du crime de Coutance, elles trouvent un terrain d'application privilégié durant son instruction judiciaire.

Le drame de la nuit

Dans la nuit pluvieuse du $1^{\text {er }}$ au 2 mai 1885, peu avant minuit, au premier étage de l'immeuble du 20 de la rue de Coutance, située sur la rive droite du Rhône dans le faubourg genevois de Saint-Gervais, Jeanne Lombardi égorge d'une "main sûre et ferme ", au moyen d'un rasoir, sa fille et ses trois garçons endormis, âgés de sept à quatre ans. "Mon idée, dira-t-elle au juge, était de me jeter à l'eau après avoir fait mourir mes enfants. Je voulais les faire mourir, craignant, moi n'étant plus là, de les abandonner à mon mari qui les aurait laissés avoir faim et avoir de la vermine ». Se "sent[ant] le cœur mort», Jeanne veut en finir avec ses enfants " comme la reine des abeilles dans sa ruche ». Après avoir crié au moins vingt minutes, après avoir "viré " comme dans un "tourbillon", elle se décide enfin. Agissant "machinalement», la mère tranche d'abord la gorge de l'aîné Pierre-Eugène (né le 7 janvier 1878) en « lui causant ». Elle continue par la "petite Joséphine» (née le 27 septembre 1880), puis frappe Emile-Elie (né le 23 avril 1879), et termine le "massacre» par le benjamin Joseph-Emile (né en 1881) qui survivra aphone. La «froide exécution accomplie», la mère égorgeuse éponge les cadavres, arrange du lilas blanc dans les mains et sur les lits des victimes. Ensuite, elle retire son tablier de cuisine bleu à carreaux blanc et son paréo rouge ensanglantés, sort pour poster une lettre informant une voisine de la "terrible résolution qu'elle venait de prendre ${ }^{15}$. Rentrée chez elle, Jeanne Lombardi avale de l'atropine mêlée à du curaçao, se couche, sombre dans le coma. 
7 Soixante minutes plus tard, son mari Joseph Lombardi remonte de sa boutique de tailleur, se déshabille et s'allonge auprès de Jeanne profondément endormie. Bientôt réveillé par les râles d'agonie de Joseph-Emile et les ronflements de sa femme, il se relève, tire de son sommeil la bonne alitée dans la cuisine adjacente, découvre le tableau du drame à la lumière d'un réverbère éclairant la chambre depuis la rue, s'habille, sort "hébété ", sans chapeau, pour chercher un médecin. Il est vite appréhendé par un policier qui le raccompagne sur les lieux du drame. Quinze minutes plus tard, le directeur de la police centrale John Cuénoud (1822-1899), spécialiste de la statistique criminelle et adepte d'Alphonse Bertillon ${ }^{16}$, deux policiers, deux médecins généralistes et un juge d'instruction investissent " gravement » la scène du quadruple égorgement. Les enquêteurs sont rejoints rapidement par le médecin-légiste HippolyteJean Gosse (1834-1901), patron de la morgue judiciaire, technicien de la photographie cadavérique et archéologue médiéviste à ses heures ${ }^{17}$. Immédiatement il brosse le portrait de Jeanne Lombardi, inconsciente. Auteur d'une thèse sur l'interprétation médico-légale des traces de sang ${ }^{18}$, il est particulièrement attentif à celles colorant le visage de la meurtrière. Leur dispersion faciale et leur étendue informe sur son mode opératoire. Effondré sur une chaise, "soupçonné d'homicide sur ses enfants", longuement interrogé, Joseph est l'objet d'un mandat d'arrêt. Vers trois heures du matin, il est conduit à la prison de Saint-Antoine, d'où il sort innocenté le lendemain matin. Ayant manqué son suicide, sa femme reprend ses esprits sur le lit conjugal à l'aube du 2 mai, après « quatre heures de soins ininterrompus ». Délirante, elle balbutie "quelques syllabes inintelligibles». Sommairement interrogée par le juge d'instruction, refusant "désespéramment » de «quitter ses enfants », elle est menée dans une cellule forte de l'Hôpital cantonal pour « récupérer ».

8 Gosse arpente les lieux du crime pour en dresser la topographie ${ }^{19}$. Ensuite, il photographie les cadavres, procède à leur levée légale et les fait conduire à la morgue de Police, située alors au chemin de l'École de Médecine (non numéroté), à l'extrémité ouest du quartier populaire de Plainpalais, sur les bords de l'Arve, face à la caserne militaire. Dès le 4 mai, entre photographies et autopsies cadavériques, analyse des «matières vomies" par Jeanne Lombardi et examen de ses vêtements, il met finalement le corps des victimes en preuves ${ }^{20}$. Externe et interne, l'autopsie des enfants Lombardi démontre qu'ils ont été égorgés, endormis et vivants. Bords linéaires, sections nettes, coupures rectilignes, profondeurs inégales: comme le montre la typologie des lésions constatées sur les corps des enfants, la « section » de leurs cous a " été faite par un instrument très tranchant comme un rasoir mû de droite à gauche ». L'autopsie qualifie et quantifie ainsi la violence meurtrière de Jeanne qui, de la main droite, a égorgé sa fille et ses deux garçons avec un rasoir. Pour réussir son projet homicide, elle a dû, avec sa main gauche, immobiliser ses enfants qu'elle blesse aux mains ou au visage alors qu'ils se débattent en tentant de parer aux chocs de la lame qui les saigne à mort. Précis, profonds, infligeant une ou deux incisions fatales, les coups de lame sectionnent entièrement ou partiellement l'artère de la tête et de la partie supérieure du cou qui assure notamment l'irrigation du cerveau. Le mode opératoire ressort ainsi du corps massacré des trois victimes. Surpris dans leur sommeil, saignés à blanc par une plaie douloureuse, Pierre Eugène, Emile Elie, Joséphine Henriette meurent d'asphyxie par hémorragie des «voies [respiratoires] aériennes ». Gosse fonde ainsi médico-légalement la réalité de l'assassinat, qualifié alors par l'article 252 du Code pénal genevois. Suffoquant de son "horrible blessure » laryngienne, Joseph-Emile a été hospitalisé la nuit du drame «dans un état 
désespéré » : les médecins tentent d'ailleurs de "faire sur l'enfant une opération très importante afin de lui rendre l'usage de la parole», selon les journaux qui apaisent l'«opinion émue» du public en suivant le rétablissement de l'unique survivant du crime de Coutance.

Funérailles dans une ville émue

9 Selon le refrain de toute la presse, Jeanne Lombardi a étouffé les « sentiments du cœur maternel ». Le tableau de l'égorgement des innocents endormis hante les esprits : «On comprend à la vue des cadavres, note le 4 mai l'échotier du Genevois dont les informations proviennent du directeur de la Morgue judiciaire, comment l'horrible scène a dû se passer: l'aîné des enfants et sa sœur ont été frappés à l'improviste, souriant à leur mère qui, pensaient-ils, allait les embrasser ; quand au pauvre Emile, qui couchait dans le même lit que la petite Joséphine et qui a probablement vu sa mère tuer celle-ci, puis lever l'arme fatale, sa physionomie exprime la terreur ». La mère égorgeuse est un «monstre moral », sa "perversité » signale sa "dangerosité», sa cruauté la déshumanise.

Dans une ville étroite comme Genève, l'« horrible drame de la nuit faisait le sujet de toutes les conversations ", note encore le Genevois (4 mai). À travers la "ville en émoi ", circulent alors les «bruits les plus contradictoires» sur l'origine du «terrible événement ». Dès le dimanche, un "véritable pèlerinage " s'organise vers la Morgue judiciaire. Pourtant, celle-ci reste fermée au public comme le rappelle le Journal de Genève (5 mai). Le choc émotionnel provoqué par le crime de Coutance ressort des funérailles des trois enfants égorgés. Dans le Genevois (4 mai), la famille LombardiDeluermoz publie une annonce mortuaire qui prévient "amis et connaissances de la perte cruelle » qu'elle vient d'« éprouver en la personne de Pierre, Emile et Joséphine ». Les funérailles sont arrangées selon le désir de Jeanne Lombardi. Incarcérée, elle obtient tout de même que la cérémonie funéraire débute au logis familial et non pas à la morgue, afin d'éviter aux victimes l'infamie posthume. Ainsi, dès $10 \mathrm{~h} 30$, encadrée par cinq agents de police, bigarrée et dominée par les femmes «venues là avec [des] petits enfants, comme si elles allaient assister à un spectacle extraordinaire», une " foule immense » est massée devant le « logis mortuaire ». Sous un ciel bas, les rues du faubourg, où les magasins sont fermés, regorgent de monde. Les fenêtres des immeubles débordent de spectateurs endimanchés. Vers onze heures, les corbillards noirs arrivent devant la boutique des Lombardi. «Couverts de lilas", les cercueils des victimes y sont hissés à bras d'hommes. Les « sanglots de quelques femmes » lacèrent le silence respectueux. Sur la première voiture mortuaire repose le cercueil du "petit Pierre » que suivent une " quarantaine de camarades ». Ensuite, les « bières des enfants cadets " sont placés, " côte à côte ", sur le second chariot funéraire. Joseph Lombardi, son père et ses deux beaux-frères s'installent dans le premier corbillard. De leur côté, le "père de Madame Lombardi » et d'«autres parents éloignés» s'assoient dans la seconde voiture. La famille est déchirée. Vers « onze heures et dix minutes », le cortège quitte le logis des Lombardi, remonte lentement la «partie supérieure » de la rue de Coutance, progresse le long de celle de Cornavin au «milieu de deux haies vivantes et compactes ", puis se dirige vers la place des Vingt-Deux Cantons, avant d'aborder les rues de la Servette, de Lyon et des Délices, pour aboutir au cimetière municipal du Lazaret à Châtelaine. Dans la ville protestante, où les processions funéraires restent discrètes, le crime de Coutance provoque certainement le plus important convoi funéraire, privé et catholique, de la seconde moitié du XIX ${ }^{e}$ siècle. Attisée par la presse et nourrie par la rumeur, la curiosité populaire est à la hauteur de l'émotion collective 
mise à vif par le quadruple égorgement. Entre la rue de Coutance et le cimetière d'Aïre, sur environ 2 kilomètres, note le 5 mai un journaliste de la Tribune de Genève, « la foule formait une sorte de cordon continu qui aurait commencé à Coutance pour finir à l'avenue d'Aïre. Combien d'hommes et de femmes, en voyant passer les trois cercueils de ces innocentes victimes, laissèrent couler leurs larmes : nous avons entendu dire beaucoup de citoyens âgés que jamais à Genève, ils n'avaient assisté à une manifestation aussi profondément émouvante. Nous sommes certainement pas loin de la vérité si nous disons qu'environ dix à douze mille personnes ont vu défiler le lugubre cortège ». Ayant difficilement accédé à la " petite chapelle ", sise à droite de l'entrée du cimetière envahi par la foule, la famille Lombardi et leurs proches assistent au service funéraire. L'office est célébré par un prêtre "visiblement ému ", l'abbé Blanc de la paroisse catholique romaine des Pâquis, où les époux Lombardi se sont mariés le 22 janvier 1877, avant d'y faire baptiser leurs quatre enfants.

11 À " onze heures trente précises ", la messe prend fin. "Croix en tête ", la procession gagne le «quartier des enfants » du cimetière, ligne numéro 7, carré B, tombes 9 à 11 . Dans cette allée, les fossoyeurs ont creusé une "seule fosse longue de six mètres environ, portant les numéros 87 à $89{ }^{21}$. Bénies par l'abbé Blanc, les bières des trois enfants y sont tour à tour déposées. "Monsieur Lombardi, le grand père, éclate en sanglots", son fils "pleure abondamment, ainsi que d'autres membres de la famille». Vers midi "tout est terminé ", les premières pelletées de terre commencent de recouvrir les cercueils couverts de lilas. De retour à Coutance, la famille endeuillée reçoit alors ce "qu'on appelle à Genève l'honneur ». Parmi les "quelques milliers de personnes qui se trouvaient réunies en ce moment à Coutance, à la rue et à la place Grenus, 866 adultes et 44 enfants ont défilé devant les parents ». À « midi et demi » tout est fini : le faubourg retrouve son activité coutumière, mais la justice doit accomplir sa tâche.

Instruction judiciaire, querelle des experts

Suivie par la presse, l'instruction du «drame de Coutance» dure une année. Mode opératoire, "personnalité ", mobile, responsabilité: les enjeux judiciaires sont nombreux. Pour cerner le profil des protagonistes et établir les "circonstances" antérieures au crime, le juge d'instruction ordonne une double enquête policière menée par les inspecteurs Alex Benoît et Müller qui interrogent une centaine d'habitants du faubourg. Ceux-ci évoquent notamment l'orgueil d'une "bonne mère " souffrant des frasques de son époux porté à la boisson. Les antécédents de la prévenue et son accès de violence homicide ressortent de ses trois interrogatoires. S'ajoutent à l'instruction, treize rapports ou « consultations » d'experts divisés sur l'« état mental », pathologique ou sain, de la mère égorgeuse et suicidaire. L'« état des frais " d'expertises atteint ainsi 80\% du coût procédural (1 262 francs sur un total de 1573,85 francs) ${ }^{22}$. Prouvé par les expertises cadavériques du légiste Gosse, le crime de Jeanne Lombardi intrigue les enquêteurs qui veulent savoir pourquoi elle a " coupé la gorge à ses quatre enfants", puis déposé sur leur lit ensanglanté deux bouquets de «lilas blanc ", avant sa tentative de suicide. Rédigé à la requête des aliénistes, un Mémoire autobiographique, écrit à l'encre noire dans cinq cahiers d'écoliers aux pages lignées, complète cette complexe investigation médico-légale qui veut cerner la personnalité de Jeanne Lombardi "s. Selon l'usage, l'autobiographie du criminel ou de l'aliéné offre, à travers sa subjectivité et sa souffrance morale, une perspective analytique de vérité reconstruite sur le mobile du passage à l'acte ${ }^{24}$. La chronique de Jeanne Lombardi donne sens rétrospectivement à une existence « malheureuse » qui aboutit au crime de 
Coutance. L'ombre de la démence meurtrière plane sur l'instruction: "Nous ne cachons pas notre sentiment: [...] nous serions soulagés si l'enquête médicale nous apprenait que la femme Lombardi n'a pas la responsabilité de ses actes ; un pareil crime paraît tellement contraire à la nature qu'il est horrible de penser qu'il a pu être commis par une mère en possession de sa raison » : le Genevois du 7 mai évoque ainsi la «folie » de la mère égorgeuse.

Si le problème de l'aliénation criminelle de Jeanne Lombardi fascine la presse, il nourrit la querelle des experts qui examinent l'accusée. Le débat commence par le rapport daté du 31 juillet 1885 du légiste Hippolyte Gosse qui le rédige sur réquisition du juge d'instruction. Ne suivant pas la nosographie de la mélancolie énoncée par le grand aliéniste de Gratz, le baron Krafft-Ebing ${ }^{25}$, Gosse retient la thèse de la culpabilité de Jeanne Lombardi. Sa rationalité criminelle ressort de l'autopsie cadavérique des enfants systématiquement égorgés ${ }^{26}$. Contexte familial, biographie, caractère, hérédité, santé physique et mentale : entre enquête et examen de Jeanne Lombardi, détenue à l'Hôpital cantonal puis à la prison de Saint-Antoine, Gosse conclut que sa "vie et [s]es actes » identifient une «personne qui a la pleine possession de ses facultés intellectuelles ». Il récuse l'hypothèse des "troubles mentaux ", car «dans la série des actes qui se sont succédés, il n'y aucun indice quelconque d'aliénation ». Le mobile et le mode opératoire du massacre sont rationnels: "Tout est raisonné, tout est logique, c'est de la violence raisonnable, c'est de la passion, c'est du désespoir ! ce n'est pas de la folie ». La seule concession: celle de la souffrance morale et du "chagrin » de Jeanne Lombardi qui devraient atténuer sa «culpabilité ». Finalement, lors de l'audience du 31 mai 1886, après avoir lu son rapport, Gosse déclare en contradiction avec celui-ci qu'il est contraint d'en «modifier les conclusions", car il «estime que l'accusée n'[est] pas responsable de l'acte qu'elle avait commis $"{ }^{27}$.

Ténor du parti radical, député au Grand conseil de Genève (1880-1891), futur conseiller fédéral (1893) et président de la Confédération (1896), l'avocat Adrien Lachenal, " juriste consommé », défend Jeanne Lombardi ${ }^{28}$. En novembre, au «nom de la défense ", il plaide la médicalisation du dossier. Le 8 décembre, dans une " réquisition » au juge d'instruction, il réclame de nouvelles expertises pour discuter celle de Gosse. Il faut, note-t-il, que les experts disent si sa cliente " jouit actuellement de la plénitude de ses facultés et s'ils estiment qu'au moment de la perpétration du crime, elle était dans son bon sens et doit être en conséquence considérée comme responsable de ses actes " ${ }^{29}$. Ayant déjà désigné comme "expert le professeur Vaucher», le parquet propose que la défense mande un second expert et le juge un troisième. Il s'agit d'examiner le «présent » et le "passé de l'inculpée ». Il importe de sonder son «état mental ».

Ainsi, sur «réquisition» du juge d'instruction, l'obstétricien et professeur à l'Université de Genève André-Henri Vaucher rédige le 14 février 1886 un « rapport de minorité concluant à la responsabilité de Jeanne Lombardi", vaincue par sa «vie infernale », sans remords depuis le crime, mais dont l'« état de santé actuel ne réclame pas son entrée dans un asile ${ }^{30}$. Lors du procès, le ministère public basera son acte d'accusation sur cette expertise pour réclamer l'emprisonnement de l'accusée. Citant pêle-mêle l'affaire Marie Jeanneret, les médecins, légistes ou aliénistes Hippocrate, Esquirol, Brierre de Boismont, Le Grand Du Saulle, Ball, Krafft-Ebing, Tardieu et Liman, Vaucher récuse la thèse de la mélancolie («lypémanie»), pour conclure en retenant l'atavisme identitaire de Jeanne Lombardi. Par souffrance morale, elle se serait vengée 
contre la famille de son mari en accomplissant son «funèbre devoir »: "La prévenue est Savoyarde ; pour qui connaît le caractère de cette population ne s'étonne nullement des actes et de la tenue de cette femme. Cette partie de notre frontière offre une population qui a un caractère tout particulier. Très laborieux, persévérants, têtus, orgueilleux, présomptueux et dominés par dessus tout par le besoin d'acquérir. Comme ils le disent, il faut faire sa maison, aussi sont-ils durs pour eux comme pour les autres. Ils sont âpres au gain, ils poussent l'honneur de la famille très loin, une pendaison, un suicide, un crime, est une tache indélébile pour eux. La femme Lombardi ressort de ce pays, toutes ses allures le montrent ${ }^{31}$.

Datée des 22 et 23 février 1886, réclamée par le juge d'instruction, l'expertise des docteurs Long et Auguste Châtelain (alors anciens directeurs des cliniques suisses de la Métairie et de Préfargier ${ }^{32}$ ) enracine la thèse de la folie criminelle dans l'instruction du drame de Coutance. Selon ces médecins travaillant notamment sur la traitement légal des aliénés incurables, l'accusée a " commis son acte sous l'influence d'un état mental pathologique ». Elle a agi sous l'« influence d'une dépression mélancolique avec idées obsessives qui lui ôtait son libre arbitre ». "Irresponsable», elle a obéi à un "raptus mélancolique » qui lui a permis de supporter une "souffrance psychique intolérable». L'amnésie suivant le passage à l'acte prouve le "caractère convulsif de l'acte ». Pour forger leur thèse, les médecins suivent aussi l'avis de Krafft-Ebing qui évoque la " conception délirante » des parents tuant leurs enfants dans les mêmes circonstances morales que Jeanne : « Les motifs sont pathologiques et non criminels, spontanés et non librement choisis. Le malade agit sous la pression d'une contrainte psychologique qu'il ne peut briser; il agit automatiquement, par réflexion physiologique et non volontairement». Cette "peinture du mécanisme psychologique de l'acte mélancolique ne s'applique-t-elle pas trait pour trait, mot pour mot à Jeanne Lombardi? Nous n'avons rien à y ajouter ", concluent les deux aliénistes qui plaident l'irresponsabilité de l'accusée, dont les contradictions comportementales - raison, déraison -, ont une "valeur entièrement pathologique ». Jeanne a égorgé ses enfants sous l'influence d'un « état pathologique » la privant de son « libre arbitre " ${ }^{33}$.

Depuis son étude située rue du Marché, Lachenal sollicite alors directement le baron Krafft-Ebing auquel il remet les expertises de Gosse et de Châtelain ${ }^{34}$. Dans son rapport daté de Gratz le 12 avril 1886, Krafft-Ebing, approuve Châtelain mais récuse Gosse qui l'a «mal compris» en tirant des conclusions erronées de ses thèses sur la "mélancolie» et la souffrance morale. L'aliéniste autrichien diagnostique la folie criminelle chez Jeanne Lombardi. "Névropatiquement prédisposée», "dérangée psychiquement », elle est une " aliénée digne de pitié » qui n'était pas « libre d'esprit au moment du crime». Le quadruple égorgement est en fait un "suicide combiné », comportement classique des mélancoliques qui tuent leurs enfants puis se suppriment : "Incapables eux-mêmes à cause de leur mélancolie de supporter plus longtemps l'existence, les malheureux de cette espèce ne peuvent cependant pas se résoudre à laisser après eux, dans ce monde de désolation, ce qu'ils ont de plus cher, et voilà comment ils en arrivent au meurtre de leurs propres enfants, chose qu'en psychologie on devrait appeler avec plus de raison un suicide combiné ${ }^{35}$.

18 "Malade d'esprit» aux "impressions faussées", Jeanne Lombardi ne peut être condamnée par la justice, car, selon l'aliéniste, elle est irresponsable : « La réunion de la malheureuse mère à ses enfants par la main du bourreau, serait peut-être un bienfait pour elle, dans tous les cas, ce serait un meurtre judiciaire commis sur une aliénée digne 
de pitié ${ }^{36}$. Le 18 avril 1886, dans un bref rapport, le docteur Eugène Rapin, auteur en 1859 d'une thèse à Strasbourg sur l'inflammation des vésicules séminales et des canaux éjaculateurs, médecin qui avait été consulté par Jeanne Lombardi dès 1879, diagnostique aussi chez elle des " antécédents cérébraux ", l'aliénation et les «troubles intellectuels " pour énoncer son irresponsabilité qui ne diminue en rien sa dangerosité criminelle ${ }^{37}$. Egalement mandaté par Lachenal, l'aliéniste genevois Paul-Louis Ladame, élève du psychiatre allemand Griesinger et alors membre associé étranger de la Société médico-psychologique de Paris, rédige le 15 mai 1886 une « consultation médico-légale sur l'état mental de Jeanne-Emilie Lombardi ${ }^{38}$. En 1886 et 1887, Ladame publie la première « Relation de l'affaire Lombardi » dans la revue médico-légale de son collègue Alexandre Lacassagne ${ }^{39}$. Après avoir visité et examiné plusieurs fois l'inculpée détenue à Saint-Antoine, étudié les rapports médico-légaux et psychiatriques versés au dossier judiciaire, ainsi que lu l'autobiographie de Jeanne Lombardi écrite en prison, Ladame note que son état mental est "apprécié d'une façon contradictoire par Messieurs les experts ». À son tour, citant notamment Déjerine, le spécialiste en "pathologie nerveuse », Westphal, psychiatre à Berlin, l'aliéniste Lasègue (" mélancolie perplexe »), Esquirol, Brierre de Boismont ("folie-suicide»), ainsi que son "premier maitre» Griesinger, auteur en 1845 d'une monographie sur les maladies mentales où le «meurtre des enfants » est pensé comme un symptôme du comportement suicidaire, il soutient la thèse de la "folie-suicide» pour donner sens au crime de Coutance. Ce diagnostic récuse la compétence psychiatrique du médecin légiste qui base son rapport en évoquant à charge la normalité des "facultés intellectuelles" de la meurtrière. L'expertise de Ladame illustre la division des aliénistes d'alors en ce qui concerne la nature de la folie, les notions de discernement, de libre-arbitre, de responsabilité et d'irresponsabilité. Comme le font Gosse et Vaucher qui refusent la thèse de l'aliénation de l'accusée, les experts fondent souvent la responsabilité criminelle sur les «facultés intellectuelles » et la rationalité du passage à l'acte. Pour Ladame, la raison ne signifie pas absence d'aliénation. Selon lui, Jeanne Lombardi est en «pleine possession de son intelligence ", particulièrement lorsqu'elle égorge ses enfants. En conséquence, son « crime n'est pas le crime d'une folle au sens ordinaire donné à cette expression. Dans ce sens seulement, en prenant le mot "fou" comme synonyme d'une personne qui déraisonne nous pouvons dire avec Messieurs Gosse et Vaucher que Madame Lombardi n'était pas folle en commettant son crime ». La clef explicative du quadruple égorgement est ailleurs. Selon Ladame, d'autres "formes d'aliénation mentale " existent. Entre mélancolie et psychose, elles sont "plus profondes, plus insidieuses ». Elles ne "peuvent être reconnues que par les aliénistes». En supprimant le «libre arbitre " du sujet, elles «laissent intactes ses faculté intellectuelles, sa mémoire, sa raison, et son jugement ». Ces « formes de psychose », continue Ladame, appartiennent aux " états pathologiques mentaux », soit "folie des sentiments, folie affective, folie morale, folie des actes». Elles traduisent des «états de dépression psychique dont le type est la mélancolie sous toutes ses formes ». Pour ses proches, le mélancolique " paraît absolument raisonnable ", même si les «symptômes qu'il présente ne peuvent échapper à son entourage ». L'aliéné affirme qu'il se «tuera», qu'il "commettra un meurtre ». S'il n'est pas interné à temps dans un "asile où il trouvera les soins et la protection nécessaires, il ne tardera pas à mettre à exécution ses funestes projets ». "Telle a été [...], la malheureuse destinée d'Emilie Lombardi». "Anesthésie psychique ", " mélancolie » et " complication de l'hystérie »: Ladame démontre en ces termes la névrose de l'accusée, compatible avec la rationalité de son crime. «Le suicide 
de Madame Lombardi et le meurtre de ses enfants relèvent conséquemment de la pathologie ». Le crime de Coutance est " un suicide et non pas un meurtre ", conclut l'aliéniste. "Un suicide d'aliéné », précise-t-il dans ses conclusions. Lorsque l'accusée « détruit ses enfants, c'est qu'elle se détruit elle-même». Sur le plan pénal, elle « est donc irresponsable»: sa maladie mentale est fondée, si elle est pensée hors des catégories réductrices des facultés intellectuelles, de la rationalité ou de l'irrationalité ${ }^{40}$.

19 L'instruction terminée, l'acte d'accusation établi, que faire de l'accusée jugée ? Jeanne Lombardi encourt l'emprisonnement à vie, car la peine capitale a été abolie à Genève en mai 1871. Sera-t-elle néanmoins mise au bénéfice de l'article 52 du Code pénal genevois de 1874 ? Ce texte reprend les principes de l'article 64 du Code pénal français de 1810 en usage à Genève jusqu'à la promulgation du code cantonal. Il stipule qu'il n'y "pas d'infraction lorsque l'accusé ou le prévenu était en état d'aliénation mentale au moment où le fait incriminé a eu lieu ou s'il a été contraint par une force à laquelle il n'a pas pu résister ${ }^{41}$. Est-t-elle une meurtrière rationnelle qui a prémédité sa «férocité » selon le procureur général? Au contraire, son geste homicide prouve-t-il son «aliénation"? Dans le cas où le jury prononcerait l'acquittement de l'accusée, il faut donc prévoir son "placement à l'hospice des Vernets", comme le réclame avec succès dès le 26 mai Lachenal au Conseiller d'État du Département de justice et police. L'avocat suit l'avis de Ladame qui souligne qu'elle est « dangereuse pour elle-même et pour les autres ${ }^{42}$. Responsabilité versus aliénation: ces deux hypothèses médicolégales nourrissent le procès mémorable de Jeanne Lombardi, présidé par le juge Bard, devant lequel déposent quatre-vingts témoins à charge ou à décharge. Dans le palais de justice de Genève transformé en place forte, les débats suspendent la vie locale du lundi 31 mai au mardi au $1^{\text {er }}$ juin 1886.

Guérie et libre

20 «Humainement» plaidée par l'avocat Adrien Lachenal, la thèse de la «maladie mentale», basée sur les dix expertises psychiatriques et médicales démontrant l'irresponsabilité pénale de l'accusée, l'emporte. Elle met en pièce celle de la « responsabilité » criminelle, proposée par deux experts ${ }^{43}$. Celle-ci est soutenue par le Procureur général Alfred Burgy qui pointe le libre-arbitre de l'accusée. En reprenant son «Acte d'accusation" du 25 mai qui accuse Jeanne Lombardi des «crimes de meurtre et de tentative de meurtre, commis avec préméditation », il convainc mal les douze membres du jury populaire, tirés au sort parmi une liste de quarante hommes (négociants, artisans, agriculteurs) nés entre 1827 et $1862^{44}$. Face aux arguments du parquet fondés sur l'enquête judiciaire et les avis médico-légaux de Gosse et de Vaucher, Lachenal tient bon ${ }^{45}$. Il marque un point capital lorsque Gosse retire les conclusions de son rapport démontrant la volonté lucide de Jeanne Lombardi. La volteface du légiste prive le parquet de sa principale pièce d'accusation. Avant la clôture des débats, le juge donne une ultime fois la parole à Jeanne Lombardi en lui demandant si la haine explique son geste. Elle persiste dans son projet morbide en déclarant d'une voix atone : «Ce n'était pas par haine pour mon mari dit-elle, c'était pour ne pas laisser mes enfants derrière moi. Le jour où mon petit cadet me sera donné, je lui en ferai autant et je me suiciderai. Ce n'est pas de la haine, c'est un ver rongeur ${ }^{46}$.

21 S'étant retiré pour débattre, le jury revient devant la cour pour répondre aux deux questions concernant les quatre victimes: Jeanne Lombardi est-elle «coupable d'homicide volontaire »? A-t-elle agi avec " préméditation »? Les jurés répondent non 
pour la première demande, ils ne donnent aucune réponse pour la seconde. Finalement, ils sont divisés sur la responsabilité de la mère égorgeuse : six voix favorables à la culpabilité, contre six voix pour l'irresponsabilité de l'accusée ${ }^{47}$. À Genève, en cas d'égalité des voix, la procédure pénale légalise la solution la plus favorable à l'accusé ${ }^{48}$. Ainsi, le juge peut prononcer l'acquittement de Jeanne Lombardi, «dangereuse pour elle-même et les autres». Le verdict étant tombé, elle est alors immédiatement internée à l'asile psychiatrique des Vernets, sous le faux nom de "Jeanne Moral », pour ne pas «agiter les malades " ${ }^{49}$. Dans la Tribune de Genève du 5 juin, un brûlot signé Vindex déplore l'issue du procès Lombardi en dénonçant le raffinement nouveau de la « notion de responsabilité » criminelle et en fustigeant l'«institution des médecins et des légistes officiels ». Incertaine en ses fondements, la psychiatrie mène les juges au laxisme et prépare la récidive des criminels fous : « Maintenant la curiosité des gens de justice a ouvert les portes du palais de justice à la pathologie. Le crime n'est plus que le résultat fatal d'un état morbide et le criminel n'est qu'un malade. La faculté de médecine remplacera le tribunal dans l'œuvre de préservation sociale et dans le mesurage de la culpabilité. L'éloquence judiciaire se retrempera dans la source qui vient de jaillir. "Atavisme", "auto-suggestion", "hypnotisme", etc., le moindre clerc d'avocat va jongler avec le jargon nouveau. Sera-ce un mal? Non, si messieurs les malfaiteurs sont réduits à l'impuissance de nuire et si chacun reçoit le salaire de ses actes. Oui, si la société n'est que la dupe de ses instincts humanitaires ou d'une sensiblerie puérile. La femme Lombardi a été internée d'office aux Vernets. C'est bien. Mais si dans quelques mois les docteurs de l'établissement, après une série d'observations concluantes, affirment qu'elle n'est pas folle, ou qu'elle est guérie, qu'arrivera-t-il ? On devra la remettre en liberté. [...] Et si après sa sortie, elle retombe dans son mal précédent ou que dégagée de toute contrainte, elle recommence et achève son œuvre monstrueuse. [...] L'hypothèse n'est pas invraisemblable. [...] Cela ne démontre-il pas l'insuffisance de notre loi répressive fondée jusqu'à présent sur le principe très respectable de la rénovation morale du criminel, mais devenu inefficace depuis l'avènement des nouvelles doctrines psychiques. La conscience publique se révolte à voir une femme - échappant à la cour d'assises grâce aux contradictions des docteurs - reprendre ensuite dans la société une place qu'aucun pouvoir ne peut actuellement lui enlever. Cette rentrée soulèverait une réprobation unanime et cependant elle sera possible dès que les médecins auront signé le certificat de guérison $[. .]$.$» .$

22 Le procès de Jeanne Lombardi transforme pourtant la jurisprudence criminelle genevoise. Avant cette affaire, on ne pouvait à Genève interner légalement un aliéné criminel. Au préalable du procès, il fallait négocier avec le Département de justice et de police pour obtenir l'internement arbitraire dans un asile. La "thèse de l'aliénation » gagnée par Ladame devant les Assises contraint rapidement le législateur à moderniser le Code de procédure pénale en prévoyant la question explicite de l'«aliénation mentale ». Formulée le 19 mars 1887, exécutoire dès le 27 avril suivant, la nouvelle loi stipule : «Si le ministère public, l'accusé ou le prévenu le requiert, et si les débats ont porté sur ce point, le Président de la Cour pose subsidiairement au jury cette question : "L'accusé a-t-il agi en état d'aliénation mentale ?" Le Président peut aussi poser cette question d'office. En cas de réponse affirmative, l'acquittement est prononcé » ${ }^{50}$. Ainsi, le dénouement du cas Lombardi aboutit à un " progrès juridique et social » selon Ladame. De manière indiscutable, le procès a "montré une lacune de notre loi de procédure pénale qui ne permet pas à la cour criminelle de faire enfermer 
l'accusé dans une maison d'aliénés comme cela se pratique en France. À Genève, il a fallu tourner cette difficulté d'avance et obtenir avant la jugement une déclaration du Département de justice et police constatant qu'il internerait le femme Lombardi, si elle était acquittée [...]. En gagnant ce procès $\mathrm{M}$. l'avocat Lachenal a fait reconnaître qu'il y avait certaines modifications capitales qui devaient être introduites dans les principes du droit pénal, il a montré que l'on ne pouvait plus se contenter de faire seulement la distinction entre le coupable et le non coupable, mais que l'on devait aussi séparer le non coupable dangereux des non dangereux; il a découvert ainsi une perspective de l'avenir juridique pénal auquel travaillent tous ceux qui étudient les questions de l'anthropologie criminelle et qui lui seront reconnaissants d'avoir ainsi mis son beau talent au service de cette grande cause ${ }^{51}$.

Brisés par la souffrance, tenaillés par la haine, les deux époux sont rapidement demandeurs en divorce. Le 27 novembre 1886 la séparation est prononcée. Si Jeanne est internée dans un "intérêt d'ordre public et de sécurité, elle n'est pas légalement interdite ». En outre, selon les conclusions du ministère public, la "garde du mineur Joseph-Emile » ne peut revenir ni à sa mère, ni son père qui ne " paraît pas remplir les conditions d'ordre et de moralité nécessaires ». Elle est donc confiée à Alphonse Patru, maitre-boulanger aisé à Genève qui assurera son éducation jusqu'au terme de son apprentissage (typographe, lithographe ?) ${ }^{52}$. Ayant en poche un passeport délivré sur autorisation du Département militaire, Joseph Lombardi émigre dès le 21 décembre 1887 en Algérie où, oublié de tous, il meurt le 28 ou le 29 septembre $1903{ }^{53}$.

Durant son internement, ses «bulletins de santé » et son «observation » clinique décrivent Jeanne d'abord comme une patiente migraineuse, déprimée, un peu maniacodépressive ("état dépressif sur fond d'hystérie »), accablée par la perte de ses enfants. Selon une interne qui résume l'état de la patiente en 1888 ( (Observation»; " Notes inscrites au bulletin journalier»), Jeanne "parle de son crime avec un sang-froid imperturbable. Elle a voulu, dit-elle, soustraire ses enfants à l'influence de son mari qui en avait fait de mauvais sujets; si elle avait pu, elle aurait achevé le dernier. Mais à présent que Monsieur Lombardi a quitté Genève et que son enfant lui a été enlevé, elle n'a plus envie de le tuer. Elle demande même à le voir et met de côté pour lui tous les petits présents qu'on peut lui faire. Elle raconte ses malheurs domestiques, comment son mari la battait, la trompait et la volait pour donner des cadeaux à ses maîtresses. Tout cela est dit tranquillement, sans exagération et pendant qu'elle rappelait ces pénibles souvenirs, jamais je n'ai vu pleurer Madame Lombardi " ${ }^{54}$. D'une "grande intelligence ", volontiers "rusée », elle devient progressivement une malade calme, combative, disciplinée, parfois "gaie", assidue aux travaux de couture, sociable. Elle s'est notamment "distinguée à l'arbre de Noël [décembre 1892] par une mise très coquette qui a attiré l'attention des invités». Si Jeanne est bien intégrée parmi les autres patientes de l'asile, son esprit est autonome. Souvent «curieuse », s'《 infiltrant partout ", elle écoute aux portes et regarde aux serrures. Serviable, elle remplace en février 1893 la lingère pendant deux mois. Le 8 décembre 1888, suite au chantage de Jeanne qui veut s'« évader » si « on ne lui amène pas son enfant », Joseph-Emile lui rend visite durant une dizaine de minutes: «Madame Lombardi n'a pas l'air très émue. Elle embrasse son enfant, lui demande comment il va, s'il est soigné, s'il la reconnaît et paraît étonnée qu'il ne lui témoigne pas plus d'amitié. Après la visite, elle pleure abondamment ${ }^{55}$. Au terme de huit ans d'internement sans grande histoire, peut-être motivée par Lachenal, elle réclame le 25 mars 1893 un " examen de sa santé » dans une lettre adressée au Conseil d'État qui reçoit sa requête le 28 mars: "Internée aux 
Vernets depuis le 2 juin 1886 à la suite d'un jugement dans lequel j'ai été reconnue irresponsable de l'affreux accident dont j'ai été l'auteur, je viens solliciter de votre bonté un examen de ma santé ; je reconnais qu'à la suite de grands chagrins de famille, j'ai été malade et ai eu l'esprit surexcité jusqu'à commettre l'attentat abominable sur ce que j'avais de plus cher au monde; mais depuis longtemps déjà je me suis rétablie, le chagrin que j'éprouve de mon passé m'en est une garantie ; mon désir le plus ardent est de retrouver ma liberté pour la conserver, pour mon travail, pour l'entretien physique et moral de mon cher enfant que Dieu a laissé vivre, et cet enfant n'a actuellement personne qu'une amie qui n'est plus jeune. Je vous prie donc Messieurs de prendre ma demande en sérieuse considération pour faire examiner mon état mental et constater qu'il ne reste rien de l'état de surexcitation dans lequel je me trouvais en 1885 et 1886 . Dans l'espoir que vous vous voudrez bien donner suite à ma prière, recevez Monsieur le Président et Messieurs les membres [du Conseil d'Etat] l'assurance de ma Considération distinguée/Signé : Jeanne Emilie Délermuoz, divorcée Lombardi ${ }^{56}$.

Contre toute attente, Jeanne obtient gain de cause. À la fin du mois d'octobre 1893, elle est examinée par la célèbre aliéniste Auguste Forel (1838-1931), alors professeur à l'Université de Zurich ${ }^{57}$. Le médecin, notamment intéressé à la question sexuelle des classes laborieuses et à l'hérédité de l'alcoolisme, est secondé par les docteurs Johannès Martin (directeur des Vernets) et Wilhelm von Speyr de l'Université de Berne, tous deux spécialistes de la maladie mentale et de sa prophylaxie sociale ${ }^{58}$. Datée du 28 octobre, leur brève expertise facturée 500 francs, estime que la patiente est guérie de sa «mélancolie hystérique, ainsi que des obsessions qui ont été la cause directe de son crime » ${ }^{59}$. Par l'intermédiaire du Département de Justice et Police, ce rapport favorable est communiqué le 3 novembre 1893 au Conseil d'État qui ordonne la «libération conditionnelle » de Jeanne Deluermoz ${ }^{60}$. Elle sort le 10 mai 1894, «libre » et " guérie » de l'asile. Dotée d'une pension par l'Hospice général, contrainte de quitter le territoire genevois pour des raisons de "sécurité publique » et devant renoncer à revoir son fils qui a survécu au crime de Coutance, Jeanne Lombardi gagne la France voisine. Pour l'instant, elle échappe à l'enquête historique.

«Rien ne parle à mon âme »

Qui est véritablement Jeanne Lombardi, examinée, jugée et moralisée par des hommes? Qu'en est-il du sens de son geste désespéré ? Ses aveux à la justice sur les motivations du quadruple égorgement suffisent-ils à expliquer le mal qui la mine? Quel est ce «ver» moral qui la ronge? Au-delà de l'instruction judiciaire, son drame continue d'intéresser les aliénistes, car « dès le début de l'instruction, des doutes s'élevèrent sur l'intégrité des facultés intellectuelles de la prévenue ", selon le docteur Albert Giraud, directeur-médecin de l'Asile de Fains, doctrinaire du patronage psychiatrique des "aliénés dangereux ", libérables après un internement asilaire, mais potentiellement récidivistes ${ }^{61}$. Amplifié par sa publicité médiatique, le quadruple égorgement susciterait une nouvelle pathologie mentale, impulsive dans son accomplissement maniaque: l'«obsession du meurtre par contagion mentale». Paul-Louis Ladame affirme avoir traité des Genevoises démoralisées par le crime de Coutance. En 1886 et en 1892 encore, ses patientes veulent assassiner leurs enfants, puis se suicider « comme la femme Lombardi » ${ }^{62}$. Selon certains aliénistes, la causalité immédiate du drame de Coutance s'ancre dans la démoralisation de Jeanne Lombardi qui imiterait l'exemple morbide d'une autre femme suicidaire qu'elle évoque dans son autobiographie ${ }^{63}$. Affirmant en 1896 que la "contagion du meurtre " obéit à deux conditions (" pénétration d'un élément morbide dans un terrain préparé »), l'aliéniste Paul Aubry 
retient dans sa nosographie de la folie les échos morbides de l'affaire Lombardi ${ }^{64}$. Même idée de démoralisation sociale reprise dès 1891 par John Cuénoud dans sa croisade contre la "publicité des actes criminels ou obscènes »: "L'idée de tuer ses enfants lui vient, dit-elle : comme une femme l'a fait. Ce qui était dans le journal ». En ces termes qui paraphrasent l'autobiographie de Jeanne Lombardi, il évoque son cas pour dénoncer la «contagion du mal» happant les individus moralement faibles, lecteurs de la presse populaire et de faits divers criminels qu'ils ne peuvent mettre à distance ${ }^{65}$.

Au-delà de l'enquête judiciaire qui génère le cas psychiatrique exemplaire jusque dans le conflit des experts, au-delà de l'enquête historique qui tente de nouer le sens social et médico-légal du crime de Coutance remis dans le contexte de la sensibilité urbaine des années 1880, la figure de Jeanne Lombardi échappe à la nosographie positive de l'aliénation - folie de l'intelligence, soit délire, dysfonctionnements organiques, dépression psychique-que formulent les aliénistes de son temps. Certes, la dangerosité du drame de la nuit réside dans son exemplarité négative qui aboutit à la moralisation sociale. "Cet abominable attentat, note le 9 mai 1885 La Semaine religieuse de Genève (organe du protestantisme évangélique), est donc en partie le fruit du milieu moral dans lequel il a surgi ». Selon le Semeur vaudois - journal évangélique et national, le drame de la nuit remplit en outre les vues cachées de la providence : « Le crime de Coutance, note le 15 mai 1885 un éditorialiste de cet hebdomadaire protestant, est un de ces affreux malheurs, un de ces horribles scandales nécessaires, dit le Seigneur, sans doute pour nous rappeler l'infirmité et la corruption de notre nature ».

Or, bien enchevêtré dans ce programme de moralisation sociale et religieuse qui vise à effacer l'impact public du drame de la nuit, le diagnostic médico-légal du cas Lombardi illustre l'incertitude des experts à qualifier scientifiquement la folie meurtrière selon une nosographie positive. Le pasteur Steiger qui signe le 9 mai 1885 un long éditorial («À propos du Drame de Coutance ») dans L'Alliance libérale - Organe du christianisme libéral, mesure l'« émoi » collectif provoqué par le quadruple égorgement. Selon lui, le drame recoupe le "nœud inextricable d'une énigme psychologique ». Détermination criminelle, chagrin, souffrance morale et physique, dépression, mélancolie, vitalité brisée par des déceptions répétées, névrose : la personnalité de Jeanne Lombardi ne coïncide en effet avec aucun diagnostic définitif proposé par les experts, bien que Ladame ait montré devant la cour que la maladie mentale ne rime pas avec irrationalité. Dans son autobiographie, un poème donne peut-être du sens à cette "énigme psychologique ", éclairée par le ressassement existentiel d'une douleur matricielle qui aboutit au quadruple égorgement. Faut-il suivre Jeanne lorsqu'elle place l'origine et la clef du drame de la nuit dans le deuil précoce de sa mère ? « Rien ne parle à mon âme/pas une seule flamme d'amour/un jour./Pas de mère chérie/dont la douce voix prie/pour moi ;/qui m'ait appris des cieux/le chemin glorieux,/la foi./Non, jamais l'espérance/ne donne à ma souffrance/la main./Et le jour qui s'écoule/me voit loin de la foule,/sans pain./Aussi, quand la nuit tombe,/je m'en vais sur la tombe/qui dort./Je m'assieds et je pleure,/demandant à chaque heure/mon sort ». Jusqu'au terme de son procès, aveuglée par la subjectivité de sa souffrance morale que son internement asilaire efface progressivement, Jeanne Lombardi n'a cessé de répéter qu'elle ne pouvait pas laisser ses enfants "derrière » elle. Même au prix de leur vie et de la sienne. 

parus: L'Homme aux pensées nocturnes. Pierre Frémont. Libraire et explicateur de rêves à Genève au siècle des Lumières, Genève, Métropolis, 2000 ; Beccaria. Le droit de punir, Paris, Michalon (Coll. Le Bien commun), automne 2003.

\section{ANNEXES}

I. « Dernières volontés » : lettre de Jeanne Emilie Lombardi postée le soir du quadruple égorgement à sa voisine Madame Henriette Bailly-Ruffini.

Genève, le $1^{\text {er }}$ mai 1885,8 heures du soir

Madame Bailly-Rufini

Je regrette de vous causer autant d'ennuis, mais vous en auriez davantage, si cela n'avait pas une fin. Je voulais vous laisser la photographie de nous cinq, mais la journée a été si affreuse, je ne puis attendre. Je ne suis point folle, mais rassasiée, car je me vois dans l'impossibilité d'aller plus loin, pour moi ce n'est rien, mais ces êtres qu'il est impossible de faire de bons élèves, je vois en eux croître des germes de famille, cette famille affreuse, c'est la plus grande frayeur que j'aie, c'est qu'ils aillent les ressembler, enfin ayez pitié et soins, vous qui êtes si bonne, et moi et le pauvre Pierre on ne veut plus que je vous fréquente on [n']aime pas les momiers, alors je vous recommande les intérêts de ma sœur et de ses 3 orphelins. /Faîtes de suite [mettre] séquestre sur magasin et livres; je vous remets le plus essentiel pour vous vous verrez leur rouerie et leur ruse./Enfin j'espère qu'il ne touchera rien, il faut qu'il rende ce qui est reconnu comme argent et comme linge, il n'a que son linge de corps, meubles et autres sont [à ] moi. Je lègue ainsi, telles sont mes dernières volontés. Je regrette ce pauvre magasin, au moment où il est bien garni et bien rangé et bien payé, mais je ne regrette pas le patron, tant vous vous pourrez lui en faire sera jamais assez, et sa canaille de famille, je leur défend de porter mon deuil. /Je donne une douzaine de draps [de] coton à ma tante Josette où a été Pierre, avec mon châle qui est chez Madame Chenoz. Je donne les autres 8 à ma tante Tiennette Vanel, ma broche et mes boucles à ma belle-sœur Hortense. Ma broche où il $\mathrm{y}$ a mon cher affreux de mari, je la donne à Madame Bailly-Rufini, elle aura la bonté de mettre Pierre dedans, si on ne veut pas lui donner la photographie et bien la voici. /Tout le reste, avoir, argent, meuble, en un mot tout ce qu'il peut me venir en déshéritant jusqu'au dernier centime celui qui m'a rendu la vie aussi affreuse, vous y placerez pour élever les enfants de ma sœur, je vous laisse la charge et le soin ; il y a 6 cuillers argent que vous rendrez, ma sœur sait à qui elles sont. /Bonsoir ma bonne dame Bailly./Nous sommes heureux./Prenez des mèches de cheveux, mais je défends que la famille de bourreaux nous touche. Mes parents si pourtant mon père cesse le travail, vous aurez la bonté de le faire soigner ; faîtes de ces enfants de bons ouvriers et de bons sujets mieux que leur père.

Je vous salue tous je suis heureuse. /Emilie Deluermoz, femme du bourreau Lombardi Joseph./Mettez sur ma tombe morte martyre. 
II. Avis médico-légal donné par M. le docteur Rapin.

L'acte commis par la femme Lombardi est tellement contre nature que, à défaut d'autres preuves, il suffirait à lui seul à établir chez son auteur l'existence d'un trouble des fonctions intellectuelles. Dans les questions de criminalité où la folie est invoquée, le public est peu enclin à admettre l'irresponsabilité de l'accusé, et il se montre d'autant moins disposé à le faire que celui-ci a paru agir avec une certaine logique dans la préparation et la consommation de son crime. Cette manière de voir tient aussi bien à l'ignorance des faits sur lesquels repose l'observation scientifique qu'à la tendance habituelle du cœur humain à considérer toute mauvaise action comme le fruit d'un calcul intéressé et réfléchi.

L'étude de la psychologie pathologique conduit à des conclusions opposées. - Elle nous apprend que lorsqu'une des mille formes de l'aliénation mentale a frappé un individu de sa marque, la responsabilité de celui-ci est forcément restreinte et nul ne peut dire à quelles aberrations le malade ne sera pas tôt ou tard en proie. En pareille matière il faut s'attendre à tout.

Tel est le cas de Madame Lombardi. Appelé en 1879 à lui donner des soins, j'ai constaté chez elle, durant quelques jours, un dérangement des facultés intellectuelles (mutisme, regard effrayé) qui m'a conduit alors à m'informer s'il n'y avait pas des fous dans sa famille. Aussi à la nouvelle de son crime, ma pensée s'est-elle portée de suite aux antécédents cérébraux de ma malade, persuadé que j'avais là l'explication de l'action qu'elle venait de commettre.

Malgré sa lucidité apparente, Madame Lombardi n'en est pas moins une aliénée. Elle a, dit-on, des périodes de calme pendant lesquelles elle raconte avec précision son crime dans tous ses détails ; elle s'accuse même d'être une mère dénaturée, mais tout cela est dit sans conviction, sans cet accent du désespoir qui prouve la rentrée en possession des sentiments maternels. C'est que Madame Lombardi n'est pas sortie de la crise cérébrale, qui l'a conduite au meurtre de ses enfants. En sortira-t-elle un jour? Sa douleur alors fera pitié.

Je me résume en disant : Madame Lombardi est une aliénée ; elle est absolument irresponsable de ses actes. Mais j'ajoute qu'elle doit être considérée comme une aliénée dangereuse, si comme on le prétend, elle regrette que son dernier enfant ait survécu à ses blessures. [Signé] Dr E. Rapin. /Genève, le 18 avril 1886.

III. Examen de la femme Deluermoz divorcée Lombardi par Auguste Forel, Johannes Martin et W. Speyr.

Les soussignés docteurs en médecine, requis par Monsieur le Conseiller d'État chargé du Département de Justice et Police du Canton de Genève, à l'effet de donner leur avis sur l'état mental de Jeanne Emilie Deluermoz, divorcée Lombardi et sur l'opportunité de sa sortie de l'asile des Vernets, ont examiné longuement cette femme et pris connaissance de son volumineux dossier. Ils auront sous peu l'honneur de déposer un rapport détaillé : mais ils croient devoir présenter préalablement les conclusions de ce rapport de manière à permettre à l'autorité compétente de prendre les mesures nécessaires en vue d'une prochaine libération.

Après avoir mûrement étudié la question, les experts soussignés sont arrivés à conclure : 
1. Que la femme Deluermoz est actuellement guérie de sa mélancolie hystérique ainsi que des obsessions qui ont été la cause directe de son crime.

2. Qu'elle est atteinte d'un certain degré de dégénérescence mentale constitutionnelle qu'on peut appeler hystérie-constitutionnelle; mais que cette anomalie mentale n'atteint pas un degré suffisant pour mettre des barrières légales à l'élargissement de la dite.

3. Que la sécurité publique exige certaines mesures de précaution fortement conseillées par les experts et qui sont :

a.)L'enfant qui a survécu [Joseph-Emile, né en 1881] ne doit pas être laissé à la femme Deluermoz, mais il doit être placé sous tutelle légale.

b) La sortie de la femme Deluermoz ne doit être accordée qu'à la condition expresse qu'elle promettra solennellement et s'engagera même par écrit à rentrer à l'asile cantonal des aliénés de Genève [...], au cas où elle se sentirait de nouveau malade ou obsédée, cela à la première alerte et sans attendre que son mal empire. Cette promesse écrite entrâne naturellement pour l'autorité compétente de l'admettre à nouveau et immédiatement à l'asile, cas échéant.

c) On devra procurer à la femme Deluermoz à sa sortie de l'asile des ressources pécuniaires qui lui permettent de s'éloigner de Genève et de se créer ailleurs une situation qui lui donnera la possibilité de gagner sa vie.

Les Vernets, le 28 octobre 1893. Signé: Dr. A. Forel, professeur à l'Université de Zurich ; Dr. J. Martin, directeur de l'asile des Vernets; Dr. W. Speyr, professeur à l'Université de Berne.

\section{NOTES}

1.. Cet article présente les grandes lignes d'une monographie (à paraître) consacrée aux enjeux médico-légaux et judiciaires du crime de Coutance. Je remercie Françoise Briegel (Université de Genève) pour ses judicieuses suggestions, l'archiviste d'État de Genève Madame Catherine Santschi pour son appui, ainsi que mes collègues Yves Jeanclos (Strasbourg), Dominique Kalifa (Paris), Benoît Melançon (Montréal), et Michel Oris (Genève) pour m'avoir donné l'occasion de discuter en leurs séminaires les enjeux sociaux de l'affaire Lombardi.

2.. Procès criminel contre Marie Jeanneret. Compte rendu complet de l'enquête et des débats d'après les pièces et documents officiels, Lausanne, 1869.

3.. Archives d'État de Genève (AEG), Jur. Pén. X 737, 2 mai 1885 - $1^{\text {er }}$ juin 1886, "Assassinat de trois enfants dans la nuit du $1^{\text {er }}$ au 2 mai 1885 ». Au cabinet des manuscrits de la Bibliothèque publique universitaire de Genève (BPU), se trouvent les épreuves d'une relation imprimée de 115 pages ( 30 x $22 \mathrm{~cm}$., sur papier journal) de la plupart des pièces du dossier judiciaire de Jeanne Lombardi (Ms. Fr. 274 ; Ms. Fr. 2742, " Affaire Lombardi », papiers H.-J. Gosse). Bien composé typographiquement à la demande du médecin-légiste de Genève, Hippolyte-Jean Gosse (1834-1901), ce texte (orné des croquis du légiste) était vraisemblablement destiné à l'édition comme en témoignent les corrections manuscrites et les mentions de "bon à tirer » de sa main. Peut être imprimée en vue du procès de Jeanne Lombardi ou de son exposition dans une revue médico-légale, la relation imprimée de Gosse est le plus complète, 
actuellement, de l'affaire Lombardi. Dorénavant, nous renvoyons ainsi à cette source inédite : relation Gosse.

4.. Le Drame de Coutance. Quatre enfants égorgés par leur mère, 10 centimes, Imprimerie de Carouge, J.-F. Wirz et Cie, Rue Saint-Léger, 263, mai 1885, 15 p., avec « Plan de l'appartement des époux Lombardi ».

5.. Alfred VINCENT, L'Hygiène publique à Genève pendant la période décennale 1885-1894, Genève, Burkhardt, 1896, pp. 105 et 113.

6.. Presse dépouillée : Tribune de Genève (quotidien conservateur) ; Journal de Genève (quotidien libéral) ; Gazette de Lausanne (périodique libéral) ; Le Courrier (feuille catholique publiée les mardi, jeudi et samedi); Le Genevois (organe du parti radical).

7.. Pour un bilan de nos recherches : "Crime et châtiment : l'œil du médecin légiste », dans XVIII ${ }^{e}$ siècle, 30, Bilan et perspective de la recherche, 1998, pp. 37-50.

8.. [Jean] LA FOSSE, « Médecine-légale (medicina forensis, juridica) », Supplément à l'Encyclopédie, tome III, Amsterdam, 1777, pp. 877(b)-890(a) ; voir aussi, GILBERT, « Légale (Médecine légale, médecine du barreau, jurisprudence médicale) », dans Encyclopédie méthodique, Médecine, tome VIII, Paris, 1808, pp. 92(b)-102(b).

9.. Frédéric CHAUVAUD, Les experts du crime. La médecine légale en France au XIX ${ }^{\mathrm{e}}$ siècle, Paris, Aubier, 2000.

10.. Michel Porret, « La topographie judiciaire à Genève », dans Sociétés et représentations. Violence, Frédéric Chauvaud [dir.] 6, 1998, pp. 191-209.

11.. Traité de Médecine légale et de Jurisprudence médicale et de toxicologie (avec Georges Berryer et Gabriel Pouchet), 2 éd., Paris, Delahaye, Lecrosnier, 1886, p. XI.

12.. Henri MAUDSLEY, Le Crime et la folie, Paris, Baillière, $4^{\mathrm{e}}$ édition, 1880, p. 38.

13. Dominique KALIFA, L'Encre et le sang. Récits de crimes et société à la Belle Epoque, Paris, Fayard, 1995 ; Philippe ARTIÈRES, Dominique KALIFA, Vidal, le tueur de femmes, Une biographie sociale, Paris, Librairie Académique Perrin, 2001.

14.. Vincent BARRAS, « Péripéties genevoises de la médecine-légale fin de siècle ", Gesnerus, 3-4, 1991, pp. 485-501.

15.. Relation Gosse (voir supra, note 3), pp. 37-38, lettre de Jeanne Lombardi à Madame Bailly-Rufini que nous publions, infra, Annexe (l'orthographe et la ponctuation de la missive ont été corrigées dans la relation Gosse parfois de manière fautive).

16.. John CUÉNOUD, La criminalité à Genève au XIXe siècle, 1891, dans Bulletin de la Société genevoise d'utilité publique, VII, II ${ }^{\mathrm{e}}$ série, 1883-1892, p. 575 ; voir A la mémoire de John Cuénoud, 1822-1899, Genève, Imprimerie suisse, 1900.

17.. Hippolyte-Jean Gosse, Notes médico-légales [suivi de] La Photographie après décès, Genève, Georg, 1896.

18. Hippolyte-Jean GOSSE, Des Taches au point de vue médico-légal, Paris, 1863.

19.. Relation Gosse (voir supra, note 3), « Plan approximatif de l'appartement Lombardi », in fine.

20.. Idem, « Rapport d'autopsie des enfants », pp. 6-11.

21.. Archives de la Ville de Genève, Registre des grands enfants, Lazaret, $2^{\mathrm{e}}$ Tour, Enfants, Carré B, 1882-1920 (B 552 E 6b), la concession des tombes est établie pour Eugène Lombardi à Chambéry.

22.. AEG, Jur. Pén. X 737, pièce non numérotée, Greffe du juge d'instruction, état des frais de la procédure dirigée contre la nommée Lombardi ( 2 fol.).

23.. Nous préparons une édition de cette autobiographie.

24.. Philippe ARTIÈRES, Clinique de l'écriture. Une histoire du regard médical sur l'écriture, Le Plessis-Robinson, Institut Synthélabo pour le progrès de la connaissance, 1998. 
25.. Gosse cite La Responsabilité criminelle et la capacité civile dans les troubles intellectuels, traduit de lallemand par le Dr Châtelain, Paris, Masson, 1875, notamment pp. 68 (« mélancolie »), et 75 (« individus qui tuent leur propre enfant »).

26.. Relation Gosse (voir supra, note 3), « Rapport médico-légal sur l'état mental de Jeanne-Emilie Lombardi née Deluermoz », pp. 12-28, dont « Conclusions », pp. 26-28.

27. Ibidem, « Note additionnelle », p. 28.

28. In Memoriam, Adrien Lachenal, 1849-1918. Discours et plaidoyers, Genève, Atar, 1925, notamment « Un grand procès criminel. Plaidoirie pour Madame Lombardi », pp. 81-94. 29.. AEG, Jur. Pén X 737, pièces 137, 138.

30.. Relation Gosse (voir supra, note 3), « Rapport médico-légal sur l'état mental de Jeanne-Emilie Lombardi », pp. 61-73, notamment pp. 65, 67-71.

31.. Ibidem, p. 72.

32.. Oscar-Louis FOREL, La Métairie (Établissement médical, destiné au traitement des affections nerveuses et mentales) Nyon [Prospectus illustré], Annemasse, Soc.

d'Imprimerie d'Ambilly, 1926 ; Monique de MEURON-LANDOLT [et al.], Préfargier : 150 ans au service de la psychiatrie [1849-1999], Hauterive, Attinger, 1999.

33.. Relation Gosse (voir supra, note 3), « Rapport médico-légal sur l'état mental de Jeanne-Emillie Lombardi », pp. 29-60, notamment pp. 54, 56, 60.

34.. Relation Gosse (voir supra, note 3), « Rapport de M. le baron de Krafft-Ebing », traduction française par la défense, pp. 80-83.

35.. Idem, p. 82 (souligné par Krafft-Ebing).

36.. Idem, p. 83 (nous soulignons).

37.. Idem, 2 fol. non paginés entre pp. 83-84; voir ce rapport publié infra. Gosse ajout (p. $84)$ : «M. le docteur Rapin ayant désiré que son avis ne fut pas publié, tel qu'il l'avait rédigé, je ne l'ai pas fait imprimer, estimant que l'on ne pouvait modifier une pièce lue à l'audience. [...]".

38.. Relation Gosse (voir supra, note 3), pp. 85-108.

39.. Archives de l'Anthropologie criminelle et des sciences pénales, I, II, 1886, 1887, respectivement pp. 436-460, 52-85.

40.. Relation Gosse (voir supra, note 3), pp. 86, 87 (« psychose »), 89 (« suicide » et non pas « assassinat »), 94, 96-98 (« mélancolie », « psychose »), 101-108 (« Discussion et conclusion ", dont la thèse sur le suicide élargi aux enfants).

41.. Code pénal du Canton de Genève (21 octobre 1874), Livre I, titre V, section II, art. 52, «Aliénation mentale », p. 17.

42.. AEG, Jur. Pén X 737, pièce 523.

43.. Adrien LACHENAL, « Plaidoirie pour Madame Lombardi. Cour d'assises de Genève (1886) ", dans Fernand Payen [éd.], Anthologie des avocats français contemporains, Paris, Grasset, 1914, pp. 505-517.

44.. AEG, Jur. Pén X 737, pièce 173, « Réquisitoire », 178, « Acte d'accusation », fol [5]. «Copie de la Liste des quarante Jurés tirés au sort dans la séance de la Cour de Justice du lundi vingt-quatre mai [1886] », pièce non numérotée.

45. In Memoriam, Adrien Lachenal, 1849-1918, ouv. cité,. (supra, note 28), « L'Hommage du barreau », pp. 95-97. Le procès de Jeanne Lombardi élargit la notoriété de Lachenal « intéressé à la médecine au point de pouvoir, plus d'une fois, tenir tête sans désavantage aux experts médico-légistes de l'accusation ».

46.. Semaine judiciaire, 23, 14 juin 1886, « Cour criminelle, session des 31 mai - 5 juin 1886 », pp. 365-367.

47.. AEG, Jur. Pén. W 4, No 55 [non paginé]. 
48.. Dispositions légales concernant le jury dans le canton de Genève, Genève, 1885, IV, « La délibération des Jurés », art. 338, p. 28.

49.. BPU de Genève, Ms. fr. 2742, « Observations de Madame Jeanne Lombardi. Entrée aux Vernets le 2 juin 1886 », notes de plusieurs internes, fol. 2, 5.

50.. Revue pénale suisse [...], I, 1888, « Loi permettant de poser au Jury la question de savoir si l'accusé a agi en état d'aliénation mentale », pp. 95-96.

51.. Ladame, Archives d'Anthropologie criminelle, II, 1887, p. 85.

52.. Semaine judiciaire, 1887, 46, pp. 730-732.

53.. AEG, Registre décès, 1901-1905, fol. 328 (décès enregistré à Genève le 10 février 1904).

54.. BPU de Genève, Ms.fr 2742, fol. 4.

55.. Ibidem, fol. 6 .

56.. AEG, Annexes des RC, O.D., 266, p. 463 (leçon modernisée).

57.. Sur l'aliéniste, voir notamment: Rol MEIER (éd.), August Forel : 1848-1931, Arzt, Naturforscher, Sozialreformer : eine Ausstellung der Universität Zürich, Zürich, Herbst, 1986.

58.. Zur Erinnerung an Herrn Professor Wilhelm von Speyr, 1852-1939, Bâle, H. Boehm, 1939.

59. AEG, RC 1894, 13 juillet et 28 août, fol. 51, 268 (« notes d'honoraire » : 250 francs pour Forel ; idem pour Speyr) ; Justice et police, Dg 45, 5990 ; voir cette expertise publiée infra.

60.. AEG, RC, 1893, 2, 3 nov. 1893, fol. 640.

61.. Département de la Meuse, Asile de Fains [Prospectus], Bar-le-Duc, 1875; «L'Affaire Lombardi à Genève ", Annales médico-psychologiques. Journal relatif à recueillir tous les documents relatifs à l'aliénation mentale, aux névroses et à la médecine légale des aliénés, Paris, 1887, VII ${ }^{\mathrm{e}}$ série, V, pp. 391-414.

62.. "L'obsession du meurtre ", Actes du Troisième congrès international d'Anthropologie criminelle tenu à Bruxelles en août 1892 sous haut patronage du Gouvernement. Biologie et Sociologie, Bruxelles, 1893, pp. 41-55 (loc. cit. p. 53, souligné par Ladame).

63.. Armand CORRE, Crime et suicide. Étiologie générale, facteurs individuels, sociologiques et cosmiques, Paris, Doin, 1891, p. 226.

64. La Contagion du meurtre. Étude d'anthropologie criminelle, Paris, Alcan, 1896, pp. 2, 87.

65.. Du danger de la publicité et des illustrations des faits criminels ou obscènes. Rapport présenté au Congrès intercantonal à Berne le Mardi 29 septembre 1891, Genève, Soullier, 1892, pp. 11-12.

\section{RÉSUMÉS}

En mai 1885, le Crime de Coutance - une jeune mère de famille égorge ses quatre enfants endormis - bouleverse la population de Genève. La presse protestante et catholique transforme le drame familial en atroce fait divers. Les funérailles des enfants auxquelles assistent plusieurs milliers de personnes soulignent le traumatisme collectif causé par le geste désespéré d'une « mère dénaturée ». Cependant, ce crime illustre à Genève l'immense impact de la psychiatrie et de la médecine légale sur la justice. Du début à la fin de l'instruction et du procès, les experts occupent la scène judiciaire. S'ils sont divisés sur la responsabilité pleine ou nulle de l'accusée qui 
écrit son autobiographie, néanmoins la thèse de la folie triomphera devant les Assises. Considérée dangereuse pour elle-même et pour les autres, la mère meurtrière est internée à l'asile psychiatrique de Genève. Le procès qui fascine l'opinion publique pose la question de la folie devant les tribunaux. Une année plus tard, l'affaire permet au législateur genevois de réformer la loi sur le traitement légal des aliénés criminels. En 1893, après de nouvelles expertises psychiatriques, la mère meurtrière est libérée. Entre-temps, le crime de Coutance est devenu un cas psychiatrique discuté dans la littérature médico-légale. Il permet l'élaboration d'une nouvelle catégorie nosographique : l'« obsession du meurtre par contagion mentale ».

The crime of Coutance (Genève, 1885). In May 1885, the Crime of Coutance - that of a young mother who cut the throat of her four sleeping children-upset the population of Geneva. Catholic and Protestant newspapers transformed this family tragedy into an atrocious news in brief. The funeral of the children, which was attended by several thousand people, underlined the collective trauma caused by the maternal crime. However, in Geneva, the case illustrated the deep impact on justice of criminal psychiatry and legal medicine. From the beginning to the end of instruction and trial, the experts were on stage. If they did not agree about the responsibility or irresponsibility of the defendant who wrote an autobiography, the thesis of madness nevertheless triumphed in the court of Assizes. Considered to be dangerous for herself and for the others, the loophole was interned in the psychiatric asylum of Geneva. The lawsuit fascinating the public opinion and raised the question of madness in front of the court. One year after the verdict, the legislator amended the law on legal treatment of alienated criminals. In 1893, after new psychiatric expertise, the fatal mother was released. In the interval, the Crime of Coutance became a psychiatric case discussed in criminological literature. A new nosographic category was drawn from the crime of Coutance : the "obsession of murder by mental contagion".

\section{AUTEUR}

\section{MICHEL PORRET}

Professeur d'histoire moderne à l'Université de Genève. Derniers ouvrages parus: L'Homme aux pensées nocturnes. Pierre Frémont. Libraire et explicateur de rêves à Genève au siècle des Lumières, Genève, Métropolis, 2000 ; Beccaria. Le droit de punir, Paris, Michalon (Coll. Le Bien commun), automne 2003. 